\title{
Culture of impunity and safety of journalists: Is safe journalism a distant dream in Pakistan?
}

\author{
Sadia Jamil \\ University of Queensland, Australia
}

DOI: 10.30547/worldofmedia.1.2019.3

\begin{abstract}
Pakistan's journalists confront fatal safety risks in the line of their duty and are at the mercy of various types of pressure and extremist groups that threaten, kidnap and even murder them with almost total impunity. Despite the growing violence against journalists in Pakistan, there is a dearth of national academic studies that offer insights into threats to journalists' safety and the country's rampant culture of impunity. Therefore, using the system theory, this study explores Pakistan's issues of impunity and threats to journalists' safety in conflict and non-conflict situations. The study also analyses the country's laws for the protection of journalists' rights to freedom of expression, access to information, online and offline safety, fair trial and equal pay-scales. In addition, the study unpacks the journalists' lived experiences of safety risks in Pakistan and their perceptions regarding the country's culture of impunity. To achieve these objectives, this study uses the qualitative methods of document review and indepth interviews (face-to-face). Moreover, the study uses thematic analysis to analyse the gathered data.
\end{abstract}

\section{Keywords}

Impunity, safety risks, journalists' protection, legal system.

\section{Introduction}

Violence against journalists is a routine problem in Pakistan. Especially, the country's conflict areas of Khyber Phaktunkhwa Province, North and South Waziristan, Federally Administered Tribal Areas (FATA) and Baluchistan Province are hotspots of journalists' killing and kidnapping. In tribal areas within the Peshawar border region of Pakistan and along the border with Afghanistan, investigative journalists confront fatal safety threats. Pakistan's journalists are not only at risk of organized crimes in the aforementioned conflict areas,

Corresponding author:

Sadia Jamil, University of Queensland, St. Lucia QLD 4072, Australia.

Email: sadia.jamil@ymail.com 
but they also face diverse safety risks in the country's major cities including Karachi, Islamabad, Lahore, Peshawar and Quetta. Consequently, the Pakistani journalists are not able to practise their right to freedom of expression and they are unable to work safely (Jamil, 2017).

Reports by international organizations monitoring freedom of expression and journalists' safety levels in Pakistan suggest that the biggest challenge for local journalists is the country's existing 'climate of impunity' despite diverse threats to them (Committee to Protect Journalists, 2017). According to Committee to Protect Journalists' Impunity Index, the country ranks in the top ten of those countries that do not probe and prosecute journalists' killings and violence against them (Committee to Protect Journalists, 2018). In only two cases have the murderers been convicted by the courts including the murder cases of Daniel Pearl ${ }^{1}$ and Wali Khan Baber ${ }^{2}$, suggesting that the operators of judicial system are apathetic towards countering the impunity towards crimes against journalists.

Notwithstanding the increasing violence against the Pakistani journalists, there is a dearth of academic research that explores the issues of journalists' safety and impunity in Pakistan. Thus, drawing on the system theory, this study aims to fill this gap in the literature by providing insights into three research questions: (i) Do Pakistani laws protect the journalists' rights to freedom of expression, access to information, online and offline safety, fair trial and equal pay-scales?; (ii) What safety threats do Pakistani journalists experience while covering conflict and non-conflict situations?; (iii) How do Pakistani journalists describe the country's culture of impunity? To investigate these research questions, this study uses the qualitative methods of document review and indepth interview (face-to-face) and thematic analysis to analyse the gathered data.

Hence, this article firstly reviews literature into social system theory and journalists' safety issue in Pakistan. The article goes on explaining the methodology and results of this study. Finally, it presents the conclusion and some recommendations to counter impunity and threats to journalists' safety in Pakistan.

${ }^{1}$ The Wall Street Journal's reporter, Daniel Pearl, was kidnapped and later assassinated in 2002 in the Southern port city of Karachi. In the same year, four local people were sentenced for the assassination of Daniel Pearl, especially when Pakistan's government confronted immense international pressure.

${ }^{2}$ Wali Khan Babar was killed in Karachi in 2011. The victim was Geo Television News correspondent. 


\section{Literature review \\ System theory}

System theory builds itself on premise that a system is comprised of interlinked parts or sub systems. Any alternation in the operation of one sub-system does affect the function of other sub-systems and on the system as a whole (Bertalanffy, 1968; Fuch \& Hofkirchner, 2009; Ziemann, 2007). The theory has been widely used in many disciplines such as sociology, political science, economics and journalism. This study draws on Luhmann's social system theory that emphasizes the interdisciplinary study of a social system. He classifies social system at three levels: societal systems, organizations and interaction systems. Luhmann suggests that societal systems (such as religion, law, art, education, science, etc.) are interrelated and are 'closed systems consisting of different fields of interaction'. He defines organizations as a 'network of decisions which reproduce themselves'. And interaction systems are 'systems that reproduce themselves on the basis of communication rather than decision making' (Seidl \& Becker, 2004: 35-42; Vermeer, 2006). This study posits that journalists are part of a broader social system comprising of other sub-systems (such as legal, political and cultural systems). Their protection and safety are dependent on the proper functioning and effective networking of decisions and communication among other correlated systems (especially legal and political systems). Thus, in this study, the rationale for using the system theory is that it helps to understand the ways Pakistan's social system and other sub-systems shape or influence the journalists' experiences of safety risks and the country's climate of impunity.

\section{Journalists' safety and impunity: \\ The need for academic research in Pakistan}

In the past decade, Pakistan's media industry has considerably developed and transformed. Despite diverse challenges, the country continues to have a vocal and vibrant media landscape in the Southeast Asia. Open television discussions on issues ranging from national politics to social and cultural affairs have helped to foster informed citizenry and the culture of democratic discourse in the country. Nevertheless, there are also certain areas where the media and journalists find their freedom heavily restrained, most notably in reporting on security and religious issues (Jamil, 2014; Siraj, 2009). In addition to a lack of freedom of expression, Pakistan's journalists confront fatal safety risks in conflict and non-conflict situations both. The country is one of the most dangerous countries for journalists and it has become difficult for them to work in a safe environment (Committee to Protect Journalists, 2017). 
Pakistan's growing religious extremism and its role as a front line state on war against terrorism have resulted in a polarized society with people lacking a sense of safety and peace. Particularly, the areas bordering Afghanistan including Khyber Pakhtunkhwa province, Balochistan province and Federally Administered Tribal Areas (FATA) are the most dangerous ones for journalists because of the existence of militants and religious extremist groups. Incidents of journalists' killings and violence against them clearly indicate the severity of the situation in the country. According to a recent report by Committee to Protect Journalists (2018), 60 Pakistani journalists have lost their lives in the line of their duty since 1992. Unfortunately, those who are involved in crimes against journalists enjoy impunity and the victims do not get justice. As a result, Pakistan ranks in the top twelve of those countries that do not probe and prosecute the cases of journalists' killing and violence against them (Committee to Protect Journalists, 2018).

UNESCO effectively emphasizes the necessity of academic research within the field for promoting awareness of possible risks that journalists may confront in conflict and non-conflict situations. This is followed by the UNESCO's effort to combat impunity towards crimes against journalists. Previously, a number of international academics have also paid attention to analyse the journalists' safety issues such as: journalists' protection in conflict situations from practical, legal and humanitarian perspectives (Lisosky \& Henrichsen, 2011); organized crimes against journalists in Mexico (Relly et al., 2013); typology of digital risks to journalists (Henrichsen et.al, 2015); journalists' killings and physical targeting (Cottle et al., 2016); threats to journalists' safety in Kenya (George, 2016); challenges to journalists' protection in Nepal (Adhikary et al., 2016); freedom of expression, impunity and journalists' online and offline protections (Carlsson and Poyhatari, 2017; Larry, 2017).

In Pakistan, a very few scholars have conducted academic research that analyses threats to journalists' safety. For instance, Rana Rizwan (2014) in one of his recent studies on Media Safety in Pakistan has analysed various types of threats and challenges that are confronted by the Pakistani journalists. His research brings into discussion the эnature, intensity, variety and level of threats advanced to the journalists and the ways in which they are exposed to those threats'. Rana's research underlines the role of Pakistan's security agencies, media organizations and the journalists' unions in providing protection to them for performing their job safely and continuing with the profession. The most significant aspect of this research is the identification of diversity of threats posed to journalists in different parts of the country. However, the author believes that there is a need of unpacking journalists' lived experiences of diverse threats and 
their views about Pakistan's culture of impunity. Therefore, this study analyses the issues of journalists' protection and impunity in order to identify the existing legal and other challenges that hinder safe and free journalism in the country.

\section{Methodology}

This study has used the qualitative methods of document review and in-depth interviews (face-to-face) in order to investigate three research questions, namely: (i) Do Pakistani laws protect the journalists' rights to freedom of expression, access to information, safety, fair trial and equal pay-scales?; (ii) What safety threats do Pakistani journalists experience while covering conflict and non-conflict situations?; (iii) How do Pakistani journalists describe the country's culture of impunity? Initially, different types of documents have been reviewed for this study including the Constitution of Pakistan (1973), Access to Information Law (2004), Wage Board Award ${ }^{3}$ (2013), the proposed Bill for Journalists' Safety (2016) and Harassment of Women at Workplace Act (2010).

A total of 35 male and female journalists ${ }^{4}$ from five ethnicities (i.e. Sindhi, Punjabi, Pashtu, Baluchi and Urdu-speaking) and of religious sects (i.e. Shia and Sunni) have been interviewed to investigate their lived experiences of safety risks and views about impunity to crime against them. In terms of gender bifurcation of interviewees, the study includes 8 female and 27 male journalists. The interview questionnaire encompasses the questions relating to journalists' lived experiences of nine types of safety risks including: (i) physical risks ${ }^{5}$,

${ }^{3}$ Wage Board is a committee that is formed by the government of Pakistan for the purpose of fixing the rates of wages for journalists in the country. The board is constituted after each five years. Up till now eight boards have been formed. When Pakistan came into being there was no law for the salaries of journalists so at that time the government formed a press commission in 1954 to look after the working conditions and the wages which were being paid to the journalists at that time (The News, 2013).

${ }^{4}$ Concept of journalists in this study: 'journalists' as the subject of this study have been considered as individuals who are employed by Pakistan's mainstream newspapers and television news channels; and who are engaged in the jobs of reporting, news gathering, news monitoring, news anchoring, editing, news and current affairs programs' production and administrative jobs (such as a director and news controller).

5 'Physical risks here refer to the risks of being injured and of being subjected to any kind of physical attack that may lead to death, physical disability and harm' (Jamil, 2017). 
(ii) psychological risks ${ }^{6}$, (iii) financial risks ${ }^{7}$, (iv) legal risks ${ }^{8}$, (v) social and emotional risks ${ }^{9}$, (vi) gender-specific risks ${ }^{10}$, (vii) digital risks ${ }^{11}$, (viii) topicspecific risks ${ }^{12}$, (ix) the public risks ${ }^{13}$.

In order to select the interviewees, this study has used purposive sampling that refers to the 'selection of certain groups or individuals for their relevance to the issue being studied' (Gray et al., 2007: 105). While the interviewed journalists are from the most well-known newspapers and television news channels in Karachi (i.e. total 22 media organisations), they do have work experience in more than one city of Pakistan. For ensuring the variety of responses, journalists of diverse beats (such as politics, crime, judiciary, defence, sports, business, social and religious affairs, health and education) have been selected for this study. The names of interviewees have been replaced with numbers (ranging between 1 and 35 ) so as to ensure their confidentiality and safety. Moreover, the gathered data have been analysed thematically by using the research questions' themes.

${ }^{6}$ 'Psychological risks here refer to mental stress, trauma and pressure that may affect a journalist's ability to perform his/her job freely and safely' (Jamil, 2017).

7 'Financial risks mean the threats of job insecurity, pay-scale disparity and forced job termination' (Jamil, 2017).

8 'Legal risks include the existence ineffective laws fostering impunity for crimes against journalists; unfair trial against journalists; manipulation and abuse of laws against journalists and the existence of stringent media laws' (Jamil, 2017).

9 'Social and emotional risks include the risks of anxiety, fear, depression, offence and lower self-esteem that mainly arise from the country's social context or a journalist's surrounding environment (i.e. workplace's environment and sociopolitical environment)'. (Jamil, 2017)

10 'Gender-specific risks refer to those threats that a journalist may encounter by virtue of his/her gender such as sexual assault, rape, gender harassment, discrimination and blackmailing' (Jamil, 2017).

11 'Digital risks refer to online threats that result from hacking, abusive or threatening e-mails or mobile messages and abusive comments on social media' (Jamil, 2017).

12 'Topic specific risks refer to the threats that result from covering any specific topic' (Jamil, 2017).

13 'Public risks refer to the threats that result from the violent, unethical and abusive attitudes of local inhabitants towards journalists, such as face-to-face or online verbal abuse and physical harm or attacks' (Jamil, 2017). 


\section{Results and discussion}

Journalists' legal rights to freedoms of expression, access to information, fair trial, safety and equal pay-scale in Pakistan

Document review suggests that the Constitution of Pakistan (1973) guarantees the rights of freedom of expression and access to information with certain restrictions. The Articles 19 and 19-A (under the 18th amendment 2010) of the Constitution state: 'Every citizen shall have the right to freedom of speech and expression, subject to any reasonable restrictions imposed by law in the interest of the security of Pakistan, friendly relations with foreign states, public order, decency or morality, or in relation to contempt of court, defamation or incitement to an offence. (Article 19 of the Constitution of Pakistan, 1973)

Every citizen shall have right to have access to information in all matters of public importance subject to regulation and reasonable restrictions imposed by law'. (Article 19-A of the Constitution of Pakistan, 1973 - under the 18th amendment, 2010).

The aforementioned constitutional provisions for the protection of freedom of expression and access to information in Pakistan suffer from lacunae in terms of their explanations. The Article 19 of the Constitution of Pakistan (1973) does explain the nature of restrictions on freedom of expression, which is somehow similar to the Article 10 of the European Convention on Human Rights ${ }^{14}$. However, the Article 19-A of the Constitution of Pakistan (1973) that guarantees the right of 'access to information' does not explain the phrase 'reasonable restrictions'. The section X of the Constitution of Pakistan (1973) empowers the government with 'emergency rights' to suspend the fundamental human right of freedom of expression. For example, in November 2007, General Pervez Musharraf imposed emergency in the country and suspended fundamental human rights by using the section X of the Constitution of Pakistan ${ }^{15}$ (1973). Thus, Pakistan's

${ }^{14}$ The Article 10 of the European Convention on Human Rights (ECHR) states that (a) 'everyone has the right to freedom of expression. This right shall include freedom to hold opinions and to receive and impart information and ideas without interference by public authority and regardless of frontiers'. (b) 'The exercise of these freedoms, since it carries with it duties and responsibilities, may be subject to such formalities, conditions, restrictions or penalties as are prescribed by law and are necessary in a democratic society, in the interests of national security, territorial integrity or public safety, for the prevention of disorder or crime, for the protection of health or morals, for the protection of the reputation or rights of others'. (See Article 19 Memorandum, 2002)

${ }^{15}$ See also Dawn newspaper's report at http://www.dawn.com/news/1050371/ fia-launches-probe-into-nov-2007 
Constitution (1973) restrains the journalists' rights to freedom of expression and access to information.

Moreover, Article 10 (A) of the Constitution of Pakistan (1973) provides the right to fair trial to the Pakistani citizens. Nevertheless, not all cases of crime against journalists are registered, investigated and fairly prosecuted in the country. In addition to the climate of impunity, this study reveals 'no proper laws' that provide protection to the Pakistani journalists especially from enforced disappearances; physical, financial, legal and digital threats. Journalists' response, in this study, highlights the ineffectiveness of laws relating to the journalists' financial protection (i.e. the Wage Board Award) and physical safety (i.e. the proposed Bill on Journalists' Safety, 2016; Harassment of Women at Workplace Act, 2010). This study unpacks that there have been no recent reforms made in laws relating to freedom of expression and journalists' safety by the Pakistani government. With regard to this, a news director of a local television news channel states: 'We do have Safety of Journalists Bill (2016) and Harassment of Women at Workplace Act (2010). Practically, these laws are ineffective because both male and female journalists confront physical, financial and psychological risks $\langle\ldots\rangle$ Sadly, there has been no reform and any recent change in laws that ensure journalists' rights to freedom of expression and access to information. These rights are restricted in Pakistan $<\ldots>$ As far as journalists' financial protection is concerned, the notification for eighth Wage Board Award was handed over by Maryam Aurengzeb (former Information Minister) in $2018<\ldots>$ but let me tell you that most of the media owners pay journalists as per their own choice and journalists are not paid salaries on time in many media organizations $<\ldots>$ I think Pakistan's journalists' are not wellprotected legally' (Interviewee number 2 ).

These findings suggest that Pakistan's legal system is not functioning adequately and the practice of safe and free journalism is not possible without implementation on necessary legal reforms by the country's government and judiciary.

\section{Journalists' lived experiences of safety threats in conflict and non-conflict situations}

Interviewed journalists' response, in this study, reveals that they experience physical, financial, psychological, public, social and emotional, gender-specific and legal risks most while carrying out their routine jobs. For example, all male journalists, in this study, underline the severity of physical and financial threats to them. Interview findings suggest that the public has emerged as a potential source of physical, psychological and emotional threats to journalists in Pakistan. 
For example, almost all journalists (i.e. 32 out of total 35) highlight the ways they confront pressure, physical attack and abusive language by the public. A majority of male and female journalists (i.e. 29 out of total 35) mention media organizations as a source of threat to them. They highlight that their financial and psychological well-being is heavily affected due to owner's pressure, forced and un-notified job terminations. When talking about the legal risks and issue of impunity, both male and female journalists (i.e. 29 out of total 35), put the onus of responsibility on government for being indifferent towards introducing effective measures. Noticeably, a number of male (i.e. 19 out of total 27) and some female journalists (i.e. 3 out total 8) mention digital risks of threatening e-mails and WhatsApp messages, surveillance of their mobile phones and online communication, social media and e-mail accounts' hacking.

Findings suggest that the Pakistani male journalists confront physical threats of killing, kidnapping, injury and assault more than their female colleagues. The threat mostly comes from political parties, religious and militant groups, public, intelligence and law enforcement agencies. Participating journalists, in this study, identify certain areas that are most dangerous for the physical safety of journalists including: Khyber Phkatunkhwa Province, Federally Administered Tribal Area (FATA), Balochistan Province, Interior Sindh and Karachi. They highlight that investigative journalists are mostly attacked, and it is always difficult to cover a news story about any particular group or institution directly. According to one male interviewee: 'I suffer from anxiety and depression because of Pakistan's fearful environment. Covering political, security and religious issues means that a journalist should be ready to face pressure from political parties, military, government and extremist groups. Sometimes pressure groups approach our owner and emphasize to censor the news content and journalists often face direct death threats. I do receive life threats through mobile calls and messages $\langle\ldots\rangle$ Pursuing investigative journalism is extremely dangerous in Pakistan - especially in Karachi, Balochistan Province and the Northern part of the country $\langle\ldots\rangle$ And I think the state control is weaker in these areas as compared to the other parts of the country' (Interviewee number 22).

The author opines that the two wars in Afghanistan, non-state militant organizations' involvement in on-going fight across the Line of Control (LoC), military operations in the Northern part of the country and increasing incidents of crimes have all combined to make it increasingly difficult for journalists to carry out their routine work safely anywhere in Pakistan, resulting in their practice of self-censorship. For instance, a female news producer from a local television news channel suggests: 'In Pakistan, one cannot write freely because of threats from different corners. There is a fearful environment, which causes difficulties 
for us. We have to write thoughtfully. Some people give us direct threats too. They try to access our family. So far, many journalists have been targeted and killed $<\ldots>$ We do not have freedom of expression and we are compelled to selfcensor the news stories to protect ourselves. Several times I self-censored news stories of religious events because I didn't want to be a victim of any particular group $\langle\ldots\rangle$ Also, investigative journalists have disappeared without any clue and no proper investigation is done by Pakistan's law enforcement agencies. This is very apprehensive $\langle\ldots\rangle$ Another major problem is the public's aggressive attitude. Journalists are beaten by the masses even while reporting on issues of water or electricity shortage. This is just one little example. Sometimes, writing a single line on any cultural or religious affair can trigger public's reaction, which can lead to life threats. The problem is that we have to work in a social system which is religiously and culturally complicated and restrained' (Interviewee number 8).

These findings indicate that physical threats to journalists are not just linked with their location of work in Pakistan and any specific source of risks (such as military, political parties, religious organizations, militant or terrorist groups and so on). But it is also correlated with the nature of journalists' job or assignment that results in topic-specific threats to them. Moreover, unlike male journalists, the Pakistani female journalists suggest that they do not confront serious physical threats except of injuries and attacks while covering mob protests and political rallies. This is not surprising because the proportion of female journalists is much less in Pakistan's journalism profession, and they are not usually given assignments in risky areas (International Federation of Journalists, 2015).

Noticeably, all male and female journalists highlight their experiences of financial threats of job insecurity and forced job terminations, and unpack how it affects their mental health and news content. According to two male journalists from local television news channels:

1. 'I have suffered forced job termination once and I don't get salary on time from my current employer. We do face a lot of pressure from our owners to break the news and at times to manipulate information for their political and business interests. International organizations monitoring journalists' safety in Pakistan have no idea of how much psychological pressure we bear' (Interviewee number 31).

2. 'I have spent almost nine years in this profession. It is not easy to work freely in Pakistan. If luckily you are safe from any sort of physical threat, financial pressure can kill you. Journalists are asked to leave the organization without any prior notice, if a news story does not please the 
owner or any political party or religious group. This has happened to me once. I had to suffer severe trauma after losing my job $<\ldots>$ Even in big media organizations, journalists are not paid salaries up to three to six months. And the financial situation of journalists working in small cities and rural areas is miserable. How can we work with such mental stress? Are we really watchdogs of society? Frankly, no! We work to protect our jobs and lives' (Interviewee number 13).

Findings reveal that the Pakistani journalists are not able to work with mental harmony because of physical, financial, psychological, public, social and emotional risks. While government's restrictions and the surveillance by intelligence agencies is an old tradition of causing psychological pressure to journalists, the public and media organizations have emerged as potential threats to their psychological and emotional well-being in Pakistan. In this regard, interviewee number 28 states: 'Government, intelligence agencies, militants and political parties are always considered as the main sources of threats to journalists. Let me tell you that the public in Pakistan itself is a big threat to them. I have been beaten by public twice while covering political rallies, and the public's messages and language on social media are depressing. At times, I feel like to quit the profession because I cannot live a fearful and disrespectful life $\langle\ldots\rangle$ Within media organization, the pressure of job termination kills psychologically' (Interviewee number 28).

Furthermore, in this study, female journalists highlight that they are socially targeted and discriminated because of their gender. For example, a female news reporter suggests: 'I feel depressed due to the attitude of public when doing outdoor assignments. People do not respect my gender while passing abusive remarks and hitting me and my camera man, especially during the coverage of political rallies. I have realized that journalism is a very tough profession for women in Pakistan. Social conservatism and safety risks often become obstacles for female reporters to cover conflict stories' (Interviewee number 14).

The author believes that a lack of education and growing societal extremism are two possible reasons for the public as an emergent source of threat tojournalists in Pakistan. There is a pressing need to analyse the social attitudes towards violence and underlying factors of people's conservatism and aggression in the country. And more importantly, the author emphasises research and initiatives for protecting the mental health of journalists, in addition to promoting their physical and financial protections. In a conservative society like Pakistan, people hesitate to talk about their emotions - especially related to their job. The author views that most of the Pakistani reporters are probably happy just to have their jobs. The Pakistani journalists are highly aware that if they show any 'weakness' 
or vulnerability or talk about disorders such as posttraumatic stress disorder (PTSD) ${ }^{16}$, somebody else will be more than willing to have their job. Therefore, they keep on bearing emotional and psychological risks that actually affect their ability to perform journalistic roles meaningfully. In 2014, Peshawar University's Departments of Psychology and Journalism have established a 'Competence and Trauma Centre ${ }^{17}$ in collaboration with Deutsche Welle Akademie, which is a German media company. However, the establishment of more counselling centres is required in other provinces of Pakistan - where journalists can consult for free on their psychological and emotional problems.

Moreover, a number of journalists express their apprehensions regarding the legal system of Pakistan, which is fostering legal risks and the culture of impunity in the country. According to one of the interviewees: 'Pakistan's major problem is that laws can be easily manipulated or politicized. So, a journalist should be very careful to avoid legal risks of defamation and blasphemy. I say so because media organizations and journalist's union do not come forward to provide legal assistance for longer periods of court proceedings $\langle\ldots\rangle$ We do have the right to fair trial on paper. But the Article 10 (A) of the Constitution does not ensure the elements of transparency, decorum and judicial propriety that are the basic ingredients of fair trial. One more important aspect is lawyers' and judges' conflict of interests should be disclosed in any court trial' (Interviewee number 16).

Thus, drawing on the system theory, this study reveals that Pakistan's journalists are working in complex social, political and legal systems that lack proper functioning, transparency, values and propriety. This indicates that the scope of safe journalism is limited in Pakistan until initiatives and reforms are made at various levels.

\section{Journalists' description of culture of impunity in Pakistan}

This study reveals that impunity for crime against journalists has become institutionalized and systemized in Pakistan. When talking about Pakistan's culture of impunity, some interviewed male journalists suggest:

${ }^{16}$ US Department of Veteran Affairs defines PTSD (posttraumatic stress disorder) as 'a mental health problem that some people develop after experiencing or witnessing a life-threatening event, like combat, a natural disaster, a car accident, or sexual assault'. See details at: https://www.ptsd.va.gov/public/ptsd- overview/ basics/what-is-ptsd.asp

${ }^{17}$ Peshawar Press Club and the Khyber Union of Journalists refer journalists with issues of trauma and stress for counselling in the Competence and Trauma Centre. Therapy is free for journalists there. 
1. 'Pakistan is a safe place for criminals because they are set free without any court trial. In my knowledge, not a single person has been ever convicted for forced disappearances of working journalists. Impunity is an institutionalized concept in Pakistan' (Interviewee number 23).

2. 'Safety is not an issue for journalists only, but it is a problem for each and every person living in Pakistan. Criminals commit crimes and they are hardly apprehended by police because the law enforcement agencies neither work efficiently to pursue cases against them nor judicial system is strong enough to let this happen. We do not have a well-established national system for registering and monitoring the cases of violence against journalists. The culture of impunity is thriving well in Pakistan and I would not surprise if Pakistan ranks first in terms of impunity for crime against journalists soon' (Interviewee number 9).

3. 'Pakistan's law and order situation is pathetic. Crimes and violence occur when people lose their vision to educate and enlighten themselves. Neither there is an existence of effective law enforcement machinery nor the presence of strong judicial system to handle this situation. Laws are frequently abused and there is no concept of fair trial $<\ldots>$ I really feel disappointed to see Pakistan as converting into an illiterate, extremist and unsafe country. It is sad that Pakistan's government does not seem to be interested in bringing social, legal and political reforms to counter the problem of impunity' (Interviewee number 13).

This study finds five key reasons besides Pakistan's problem of impunity, namely: (i) no proper system to register crimes against journalists; (ii) weak judicial system; (iii) ineffective laws; (iv) the government's uninterested attitude towards reviewing laws, introducing legal reforms and establishing database for monitoring the cases of violence against journalists; (v) manipulation and politicization of laws. For most of the journalists (i.e. 32 out of total 35), in this study, the key problem is that cases are not reported and registered properly, which is flourishing the climate of impunity in Pakistan. For example, a female news reporter from an English-language's newspaper states: 'We all know that Pakistan is a conservative country and violent incidents are a routine problem here. There is a lack of education and societal tolerance in the country. But these are not just the only factors that are watering impunity in Pakistan. Journalists' unions have repeatedly urged the government to establish a system for proper investigation and effective prosecution of crime cases at federal and provincial levels. Journalists are killed, injured, disappeared or kidnapped in Pakistan and there is never actual record of such incidents. We cannot just rely on statistics provided by international organizations. Government and 
judiciary both need to play their respective roles efficiently' (Interviewee number 24).

The author opines that one effective way is to establish a judicial database specifically for crime cases against journalists and to appoint dedicated prosecutors for dealing with such cases at provincial and central levels. But it may seem like a distant dream in Pakistan - where the law and order machinery and the lower courts are in shambles because of extensive corruption and ineptitude of those who maintain these institutions.

\section{Conclusion}

This study reveals a very limited scope of safe journalism in Pakistan because journalists experience diverse safety threats that affect their physical, psychological, financial, legal, social and emotional state. The study highlights Pakistan's public and media organizations as the emerging sources of threats, in addition to militants, government, political parties, intelligence agencies and religious organizations.

Findings suggest that Pakistan's legal system and judicial framework is weak enough to provide protection to journalists and to counter the country's culture of impunity. The author believes that currently safe journalism is a distant dream and countering impunity towards crimes against journalists is too challenging in Pakistan. Therefore, constant and mutual efforts must be made at various levels with some indispensable measures. The government, media organizations and journalists' unions should pursue mutual efforts for: (i) long-term follow up of cases of journalists' killings and other cases of crime against them in order to see whether cases are adequately registered and fairly prosecuted; (ii) journalists' safety and first-aid trainings and their guidance on how to report in a violent environment; (iii) journalists' free consultation on how to recognize and deal with routine pressure, stress or posttraumatic stress disorder (PTSD); (iv) legal support to journalists in court cases; (v) the provision of financial and digital protections, medical and life insurances, safety equipment (including bulletproof jackets and medical kits); and the provision of financial compensation to journalists' families in case of work-related death or injury by the media organization and the government.

Furthermore, within the context of Pakistan, the author thinks that the culture of impunity can only come to an end when there is a tangible progress towards the fair trial of perpetrators for their despicable acts. And safety risks can be reduced to some extent, if Pakistan's journalists exercise caution for the foreseeable risks in conflict and non-conflict situations. 


\section{References}

8th Wage Board Award for news workers announced. The News, 18th September, 2013. Available from: https://www.thenews.com.pk/archive/ print/455464-8th-wage-board-award-for newspaper-workers-announced

ADHIKARY, M. \& LAXMAN, D. (2016). Supporting safety of journalists in Nepal: UNESCO Database. Available from: https://unesdoc.unesco.org/ images/0024/002456/245666e.pdf

BERTALANFFY, L. (1968). General system theory: Foundations, development, applications. New York, George Braziller.

Committee to protect journalists (2016). Journalists killed in 2016. Available from: https://cpj.org/killed/2016/

Committee to protect journalists (2017). Getting away with murder: CPJ's Impunity Index. Available from: https://cpj.org/tags/impunity-index-2017

Committee to protect journalists (2018). 1312 journalists killed between 1992 and 2018/Motive confirmed. Available from: https://cpj.org/data/killed/?stat us $=$ Killed\&motiveConfirmed

Constitution of Pakistan (1973). 1 th Amendment 2010: Article -A of the Constitution of Pakistan. Available from: https://pakistanconstitution-law. org/18th-amendment-2010

Constitution of Pakistan (1973). Article 10 (A): Right to fair trial. Available from: https://pakistanconstitutionlaw.com/article-10a-right-to-fair-trial/

Constitution of Pakistan (1973). Article 19 of the Constitution of Pakistan. Available from: https://www.na.gov.pk/publications/constitution.pdf

COTTLE, S., RICHARD, S. \& NICK, M. (2016). Reporting dangerously: Journalists killing, intimidation and security. New York, Palgrave, Macmillan.

FIA launches probe into November 2007 emergency. Dawn, 20th October, 2007. Available from: http://www.dawn.com/news/1050371/fia-launchesprobe-into-nov-2007

Freedom House (2008). Freedom of the press (country report). Available from: http://www.freedomhouse.org/sites/default/files/Country_Reports_2008.pdf

FUCHS, C. \& HOFKIRCHNER, W. (2009). Autopoiesis and critical social systems theory. In: R. Magalh es \& R. Sanchez, Autopoiesis in organization: Theory and practice. Bingley, UK, Emerald, pp. 111-129.

GEORGE, N. (2016). Supporting safety of journalists in Kenya: An assessment based on UNESCO's journalists' safety indicators. Available from: http://unesdoc. unesco.org/images/0024/002449/244914e.pdf

GRAY, P. S., WILLIAMSON, J. B., KARP, D. A. \& DALPHIN, J. R. (2007). The research imagination: An Introduction to qualitative and quantitative methods. New York, Cambridge University Press. 
HENRICHSEN, J., MICHELLE, B. \& JOANNE, M. L. (2015). Building digital safety for journalism: A survey of selected issues. Paris, UNESCO Publishing.

International federation of journalists (2015). Media and gender in Pakistan. Available from: http://www.ifj.org/fileadmin/documents/PAKISTAN.pdf

JAMIL, S. (2014). Freedom of expression and press freedom: Journalists' understandings and practices in Pakistan. In: C. Schmidt, Pakistan's media landscape: The effects of liberalization. Bonn, DW Akademie.

JAMIL, S. (2017). Freedom under pressure? Threats to journalists' safety in Pakistan. In: C. Carlsson \& R. Poyhtari, Assault on journalism. Gothenburg, NORDICOM.

LARRY, K. (2017). An attack on one is an attack on all: Successful initiatives to protect journalists and combat impunity. Available from: http://unesdoc. unesco.org/images/0025/002504/250430e.pdf

LISOSKY, J. \& JENNIFER, H. (2011). War on words: Who should protect journalists? Santa Barbara, Calif., Praeger.

Pakistan press foundation (2015). Those who murder, injure and assault journalists are almost never punished in Pakistan. Available from: http://www. pakistanpressfoundation.org/wp-content/uploads/2015/10/Report-onSafety-of Media-Workers.pdf

RELLY, J. \& CELESTE, M. (2013). Silencing Mexico: A study of influences on journalists in the Northern States. The International Journal of Press/Politics, 19(1), pp. 108-131. Available from: http://journals.sagepub.com/doi/ abs/10.1177/1940161213509285.

RIZWAN, R. (2014). Media safety in Pakistan. Islamabad, Pakistan Institute for Peace Studies.

SEIDL, D. \& KAI, H. B. (2013). Niklas Luhmann and organizational studies. Denmark, CBS press.

SIRAJ, S. (2009). Critical analysis of press freedom in Pakistan. Journal of Media and Communication Studies, 1(3), 043-047.

ULLA, C. \& REETA, P. (2017). The assault on journalism. Gothenburg, Nordicom.

VERMEER, H. (2006). Luhmann's 'social systems' theory: Preliminary fragments for a theory of translation. Frank and Timme GmbH.

Wali Khan Babar murder case: SHC overturns death sentence of convict, orders retrial. The News, 17th August, 2017. Available from: https://www. thenews.com.pk/print/224065-Wali-Khan-Babar-murder-case-SHC-overturns death-sentence-of-convict-orders-retrial

ZIEMANN, B. (2007). The theory of functional differentiation and the history of modern society. Reflections on the reception of systems theory in recent historiography. Soziale System, 13(1), pp. 220-229. 